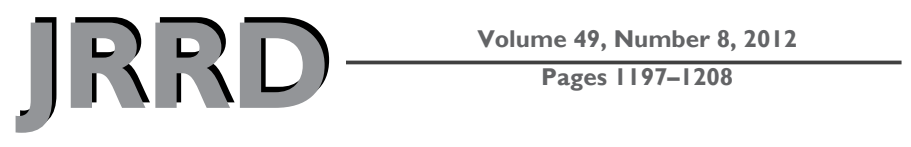

\title{
Postdeployment symptom changes and traumatic brain injury and/or posttraumatic stress disorder in men
}

\author{
Caroline A. Macera, PhD; ${ }^{1}$ Hilary J. Aralis, MS; ${ }^{*}$ Andrew J. MacGregor, PhD; ${ }^{2}$ Mitchell J. Rauh, PhD, PT, \\ MPH; ${ }^{1}$ Michael R. Galarneau, MS $^{2}$ \\ ${ }^{1}$ Warfighter Performance Department and ${ }^{2}$ Medical Modeling, Simulation and Mission Support Department, Naval Health \\ Research Center, San Diego, CA
}

\begin{abstract}
In Operation Iraqi Freedom and Operation Enduring Freedom, blast-related injuries associated with combat are frequent and can result in traumatic brain injury (TBI) symptoms that may be difficult to distinguish from psychological problems. Using data from the Post-Deployment Health Assessment and Reassessment, we identified 12,046 male U.S. Navy sailors and Marines with reported combat exposure from 2008 to 2009. Symptoms potentially associated with blast-related TBI and posttraumatic stress disorder (PTSD) that were reported immediately after deployment were compared with symptoms present several months later. Our study supports others that have found that subjects with blast-related injuries may experience the development or worsening of symptoms during the months following deployment. Additionally, our study found that those who screened positive for PTSD and TBI formed a unique group, with the presence of TBI exacerbating development of PTSD symptoms at reassessment. Providers should recognize the late development of symptoms, consider the possibility of comorbidity, and be prepared to treat multiple symptoms rather than a specific diagnostic category.
\end{abstract}

Key words: blasts, deployment, males, military, odds ratio, percent change, Post-Deployment Health Assessment, posttraumatic stress disorder, symptoms, traumatic brain injury.

\section{INTRODUCTION}

Hallmarks of the conflicts in support of Operation Iraqi Freedom (OIF) and Operation Enduring Freedom (OEF) are blast-related physical and mental problems.
While obvious physical symptoms of combat injury (such as amputation) occur among many military personnel returning from combat, other problems, specifically signs or symptoms of mild traumatic brain injury (TBI) and posttraumatic stress disorder (PTSD), may not be visible and can be more difficult to diagnose, treat, and monitor. An estimated 13.8 percent of servicemembers returned from OIF/OEF deployment were affected by probable PTSD and 19.5 percent experienced a probable TBI [1]. In the absence of visible physical injuries, the military servicemember may assume that nothing is medically wrong and not report what may be perceived to be relatively minor symptoms, such as sleeping problems or headaches. This can lead to incomplete evaluation of symptoms that are not reported immediately. In fact, the initial evaluation may be accurate because some symptoms of

Abbreviations: $\mathrm{CI}=$ confidence interval, $\mathrm{DOD}=$ Department of Defense, DSM-IV = Diagnostic and Statistical Manual of Mental Disorders-Fourth Edition, OEF = Operation Enduring Freedom, OIF = Operation Iraqi Freedom, OR = odds ratio, PCPTSD = Primary Care Posttraumatic Stress Disorder Screen, PDHA = Post-Deployment Health Assessment, PDHRA = PostDeployment Health Reassessment, PTSD = posttraumatic stress disorder, TBI = traumatic brain injury.

*Address all correspondence to Hilary J. Aralis, MS; Naval Health Research Center, Warfighter Performance Department, 140 Sylvester Rd, San Diego, CA 92106-5122; 619-5530656; fax: 619-553-0677. Email: Hilary.Aralis@gmail.com http://dx.doi.org/10.1682/JRRD.2011.07.0131 
PTSD may not even occur until several months later [24]. Even when symptoms are fully reported, there is considerable overlap with screening for TBI and PTSD because both may be present [2,5-8].

Symptoms that are often used to screen for TBI or PTSD include neurobehavioral symptoms [9], such as sleep problems, trouble concentrating, forgetfulness, indecision, and irritability; and physical symptoms, such as headache, weakness, numbness, hearing problems, and visual problems. These symptoms are among the items included in routinely administered pre- and postdeployment health assessments for all military personnel. Because these symptoms are collected at two points in time after return from deployment, there is an opportunity to understand how symptoms persist or emerge over time.

Initial positive TBI screening results may falsely identify servicemembers who do not go on to have persistent problems, in part because residual symptoms may be caused by TBI or a number of other factors such as PTSD, depression, or sleep disturbance [10]. Initial negative TBI screening results may fail to identify servicemembers who will have long-term problems resulting from the injury. Across physicians and other military health providers, remarkable consensus exists with regard to the challenges of attributing a patient's symptoms at the time of assessment to mild TBI, PTSD, or both conditions [11]. Further complicating the identification of cases for treatment and planning purposes, a number of recent studies have published seemingly contradictory findings regarding the association between TBI and postdeployment symptoms when accounting for comorbid PTSD. Several studies have concluded that after adjusting for PTSD, mild TBI is no longer significantly associated with any relevant postdeployment health symptoms, with the exception perhaps of headache [5,12]. Other studies, however, have identified an independent association between mild TBI and postconcussive symptoms such as memory and sleep problems after controlling for or stratifying by PTSD [13-14]. This apparent discrepancy between findings may be the result of vastly different target populations, sample sizes, and postdeployment data collection time points. The expectation is that symptoms following TBI and/or PTSD are dynamic with respect to time, most notably during the year immediately following the traumatic event or events. Without a clear understanding of the longitudinal development, worsening, or improvement of symptoms, important issues concerning the overlap of symptoms cannot be accurately addressed and healthcare providers are limited in their ability to make informed decisions regarding diagnosis, treatment, and prognosis of these conditions. This study will investigate changes in symptoms associated with TBI and PTSD that were reported immediately after deployment to Iraq, Kuwait, or Afghanistan and again approximately 3-6 mo later in a large sample of combatexposed U.S. Navy and Marine Corps personnel. The aims of this study are to (1) describe changes in symptom reporting across two time points and (2) evaluate the effect of TBI and/or PTSD screening status on the development and persistence of symptoms following return from deployment.

\section{METHODS}

\section{Data Sources}

The Post-Deployment Health Assessment (PDHA) (Department of Defense [DOD] Form DD2796) [15] is given to all servicemembers either during in-theater medical out-processing or within $30 \mathrm{~d}$ after returning home from deployment. The Post-Deployment Health Reassessment (PDHRA) (DOD Form DD2900) [16] contains similar questions and is usually given 90 to $180 \mathrm{~d}$ after deployment (DOD Instruction 6940.03). Beginning in January 2008, both the PDHA and PDHRA instruments were revised to include additional questions on TBI. For this study, all Navy/Marine Corps PDHA and PDHRA forms completed during 2008-2009 were obtained from the U.S. Navy's Electronic Pre and Post Deployment Health Assessment Database.

\section{Study Sample}

Our overall sample was 55,047 Navy sailors and Marines who deployed to Iraq, Afghanistan, or Kuwait in 2008-2009 and completed a PDHA following deployment and an associated PDHRA between 30 and $365 \mathrm{~d}$ later. Additionally, subjects were required to have responded "yes" to at least one of three combat experience items on the PDHA concerning (1) encountering dead or wounded people, (2) engaging in direct combat and discharging a weapon, or (3) feeling in great danger of being killed during deployment. The combat experience criterion was used to identify a background sample of servicemembers who were at risk for incurring PTSD. Because women made up only 3.6 percent of the potential combat-exposed cohort, may present for PTSD (both by symptom report or clinical diagnosis) at different rates 
than men [17], and may have higher rates of reporting other psychiatric problems such as depression and anxiety [18], they were excluded from the study sample. The resulting sample of 12,046 Navy and Marine Corps men was stratified according to PTSD and TBI screening results to yield four distinct groups: TBI-only, PTSDonly, TBI and PTSD, and a group that screened negative for both diagnoses. See Figure 1 for sampling details.

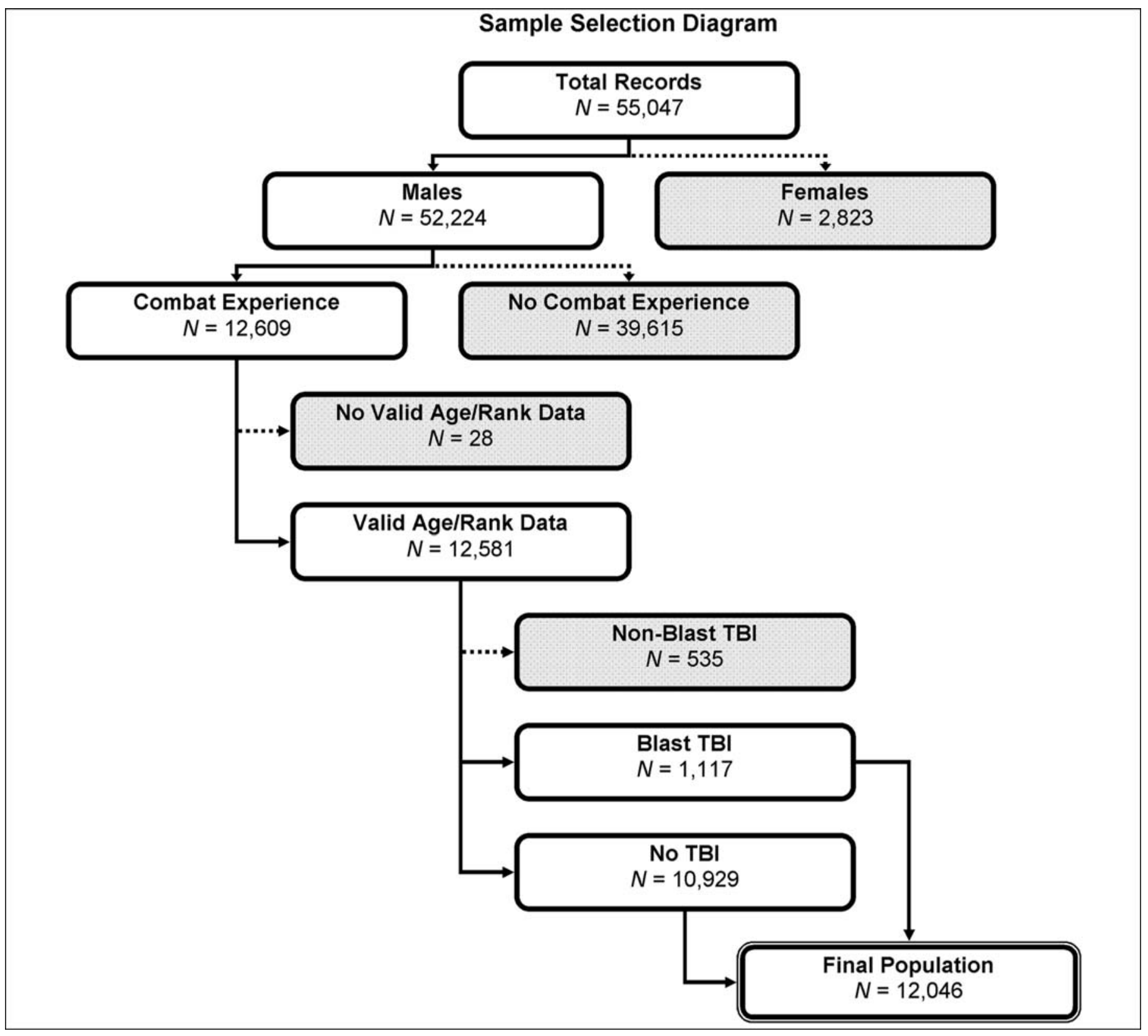

Figure 1.

Flow diagram outlining selection of final blast traumatic brain injury (TBI) and no TBI samples through application of inclusion and exclusion criteria. Dotted lines and shaded boxes indicate excluded subjects. Women were excluded because they made up very small percentage of combat-exposed cohort and may present for PTSD at different rates and report psychiatric problems at higher rates than men. 


\section{Traumatic Brain Injury Screen}

On the PDHA and the PDHRA, servicemembers were asked whether they experienced a blast or explosion, vehicular accident/crash, fragment or bullet wound above the shoulders, fall, or other injury involving the head during deployment. Following a positive response to the injury question, servicemembers were asked whether they immediately "lost consciousness or got "knocked out,", "felt dazed, confused or 'saw stars,"” or "didn't remember the event." Based on guidance distributed to military healthcare providers, and in accordance with previous studies [6], servicemembers who endorsed at least one item on the injury question and at least one of the three alteration/loss of consciousness or posttraumatic amnesia items were considered to have screened positive for a potential TBI. For this study, subjects were identified as having screened positive specifically for a blast-related TBI if they met the above criteria and responded positively to having been injured in a blast or explosion. To explore the unique sequelae of blastinduced injuries, Navy and Marine Corps personnel who did not screen positive for a blast-related TBI but did screen positive for a non-blast-related TBI were further excluded from the final sample. Therefore, all TBI references hereafter will denote blast-related TBI. Subjects who screened positive for blast-related TBI on either the PDHA or the PDHRA were included in the blast-related TBI sample (Figure 1). We decided to use these liberal inclusion criteria based on the assumptions that (1) servicemembers completing a PDHA in close proximity to their anticipated return from deployment may underreport experiences they believe will delay their return home and (2) servicemembers who report an injury event on only one of the two assessments may be doing so as a result of symptom improvement or worsening.

\section{Posttraumatic Stress Disorder Screen}

PTSD screening questions on the PDHA and PDHRA were taken from the four-item Primary Care PTSD screen (PC-PTSD) [19]. Respondents were considered to have screened positive if they answered "yes" to at least two of the four questions about having recently experienced PTSD symptoms reflecting the four dimensions of PTSD (reexperiencing, numbing, avoidance, and hyperarousal). Although the Diagnostic and Statistical Manual of Mental Disorders-Fourth Edition (DSM-IV) currently describes three clusters of PTSD symptoms (re-experiencing, avoidance/numbing, and hyperarousal), a confirmatory factor analysis conducted by King et al. identified a four- factor model as optimal using a sample of male military veterans [20]. The PC-PTSD reflects this four-dimensional structure by including separate items regarding avoidance and numbing. Among Active Duty servicemembers returning from a combat deployment, the PC-PTSD has been validated and a cutoff value of at least two items has been used in previous studies [21-22]. Servicemembers were identified as having screened positive for PTSD if they responded positively to PTSD screening items on the PDHA, PDHRA, or both assessments, consistent with the DSM-IV condition that the duration of symptoms should be at least 1 mo.

\section{Symptoms}

From a total of 24 specific symptoms on the PDHA and 23 specific symptoms on the PDHRA, we excluded symptoms if they either did not appear on both questionnaires or held no relevance to the conditions being studied (e.g., indigestion, skin diseases). A subject's “yes” or "no" response to still being bothered by a symptom at the time of assessment was the primary outcome measure used in this study. The 15 symptoms we used included questions about persistent headaches, sleeping, cognitive functions, ringing in the ears, hearing, vision, and musculoskeletal problems.

\section{Other Self-Report Items and Demographic Variables}

On both questionnaires, servicemembers were asked to rate their overall health during the past month as "excellent," "very good," "good," “fair,” or "poor.” On the PDHA, subjects were also given the opportunity to mark whether or not they were hospitalized during deployment. A two-item depression screen derived from the validated Patient Health Questionnaire is included on both instruments, and respondents were asked to select a categorical number of days during which they were bothered by "little interest or pleasure in doing things" and "feeling down, depressed or hopeless" over the past month [23]. A response of "more than half the days" or "nearly every day" to either of the items on either of the instruments resulted in a positive depression screen [4].

Age, service branch, and military rank at the time of PDHA administration were obtained from the Defense Manpower Data Center (Monterey, California). For this study, warrant officers were combined with commissioned officers because of the similarities in responsibilities. 


\section{Statistical Analyses}

Descriptive analyses of demographic and career variables were completed for all four groups defined according to TBI and PTSD screening results. The distributions of responses to questions present on one or both forms were examined across samples. For each variable, six hypotheses established a priori were evaluated using chisquare tests, and the significance level was adjusted to maintain an overall $p<0.05$. Distributional comparisons were made between samples of servicemembers screening positive for (1) both (TBI and PTSD) and neither condition, (2) PTSD only and neither condition, (3) TBI only and neither condition, (4) PTSD and no PTSD (regardless of TBI status), (5) TBI and no TBI (regardless of PTSD status), and (6) any (PTSD or TBI) and neither condition. Means and standard deviations were computed for servicemember age and the total number of symptoms reported on the PDHA and PDHRA, and analysis of variance with Bonferroni-adjusted post hoc comparisons was used to determine significant differences between the four sample means.

By subtracting the response count on the PDHA from the PDHRA and dividing the result by the count on the PDHA, we calculated percent change in symptom reporting for all symptoms across all four samples. The McNemar test was invoked to test classification agreement between PDHA and PDHRA response rates for subjects in all groups. The McNemar test was selected for its ability to use subject-level data to identify a significant difference between the two proportions of subjects with changed responses from one questionnaire to the other (those indicating "yes” and then "no," and those indicating "no" and then “yes”).

Logistic regression was used to calculate adjusted odds ratios (ORs) and 95 percent confidence intervals (CIs) for the associations between TBI and PTSD screening status and the outcome of reporting a symptom for the first time on the PDHRA. Multivariate models were constructed for each of the 15 symptoms, and the sample of subjects who screened negative for TBI and PTSD was referenced. ORs were adjusted for demographic variables, hospitalization during deployment, combat experiences, number of days between assessments, and depression screen results. For each symptom, subjects who indicated being bothered on the PDHA were excluded to model the probability of reporting a symptom for the first time on the PDHRA. Another set of adjusted ORs and 95 percent CIs was calculated by comparing the sample with both PTSD and TBI to the reference sample with PTSD only to specifically examine the unique effect of TBI among subjects with PTSD.

All statistical analyses were conducted using SAS software, version 9.2 (SAS Institute Inc; Cary, North Carolina). Significance was set at $p<0.05$ for all hypothesis testing procedures.

\section{RESULTS}

Of the 12,046 men in the study sample, 473 (3.9\%) screened positive for TBI only, 2,144 (17.8\%) for PTSD only, 644 (5.3\%) for both TBI and PTSD, and 8,785 (72.9\%) screened positive for neither condition. As shown in Table 1, TBI subjects, with or without PTSD, were significantly younger in age and more likely to be enlisted and to be Marines than subjects without TBI. The presence of a positive PTSD screen was associated with a significant increase in the likelihood of indicating fair or poor self-rated health on either the PDHA or PDHRA. Approximately 45 percent of subjects with both TBI and PTSD and 31 percent of subjects with PTSD only indicated that they had fair or poor self-rated health on at least one of the assessments compared with only 18 percent of subjects with TBI only and 13 percent of subjects from the sample without either condition. The presence of PTSD was also significantly associated with a marked increase in responding positively to one or more depression screen items on either the PDHA or the PDHRA. The presence of TBI without PTSD, however, did not appear to increase the probability of screening positive for depression.

All subjects reported high rates of having witnessed someone wounded or killed, but more than three-quarters of those who screened positive for TBI only, PTSD only, and both conditions reported having felt in great danger of being killed. Approximately 75 percent of subjects with both TBI and PTSD responded "yes" to at least two of the combat experience items, while only 29 percent of the sample without either positive screen met this condition (Table 1).

While subjects without either TBI or PTSD reported an average of 0.99 and 0.76 symptoms per assessment on the PDHA and PDHRA, respectively, the mean number of symptoms increased for subjects with TBI only, PTSD only, and both TBI and PTSD (Table 2). The only group for which the mean number of symptoms reported was 
JRRD, Volume 49, Number 8, 2012

Table 1.

Descriptive characteristics of Navy/Marine Corps personnel according to posttraumatic stress disorder (PTSD) and/or traumatic brain injury (TBI) screening status $(N=12,046)$. Data shown as $n(\%)$ unless otherwise indicated.

\begin{tabular}{|c|c|c|c|c|}
\hline Characteristic & $\begin{array}{c}\text { No TBI \& No PTSD } \\
(n=8,785)\end{array}$ & $\begin{array}{l}\text { TBI Only } \\
(n=473)\end{array}$ & $\begin{array}{c}\text { PTSD Only } \\
(n=2,144)\end{array}$ & $\begin{array}{c}\text { TBI \& PTSD } \\
(n=644)\end{array}$ \\
\hline \multicolumn{5}{|l|}{ Age $(y r)^{* \dagger \ddagger}$} \\
\hline $25-29$ & 1,691 (19.3) & $81(17.1)$ & $454(21.2)$ & $117(18.2)$ \\
\hline $30-39$ & $1,711(19.5)$ & $74(15.6)$ & $408(19.0)$ & 88 (13.7) \\
\hline$\geq 40$ & 602 (6.9) & $18(3.8)$ & $162(7.6)$ & $37(5.8)$ \\
\hline \multicolumn{5}{|l|}{ Service Branch ${ }^{\S \dagger \ddagger}$} \\
\hline Navy & $2,276(25.9)$ & $90(19.0)$ & $626(29.2)$ & $138(21.4)$ \\
\hline Marine Corps & $6,509(74.1)$ & $383(81.0)$ & $1,518(70.8)$ & $506(78.6)$ \\
\hline \multicolumn{5}{|l|}{ Military Rank ${ }^{* \S+\emptyset \neq * *}$} \\
\hline E1-E4 & $5,755(65.5)$ & $324(68.5)$ & $1,529(71.3)$ & $490(76.1)$ \\
\hline Positive Depression Screen ${ }^{\dagger \dagger *} \S \uparrow * *$ & $978(11.1)$ & $52(11.0)$ & $892(41.6)$ & $309(48.0)$ \\
\hline Hospitalized During Deployment ${ }^{\neq+* \S \dagger q \neq * *}$ & $151(1.7)$ & $41(8.7)$ & $72(3.4)$ & $82(12.7)$ \\
\hline \multicolumn{5}{|l|}{ Combat Experiences } \\
\hline Witnessed Wounded or Killed*§‡ & $5,953(67.8)$ & $347(73.4)$ & $1,362(63.5)$ & $514(79.8)$ \\
\hline Discharged Weapon ${ }^{* \dagger \uparrow \neq * *}$ & $1,463(16.7)$ & $226(47.8)$ & 388 (18.1) & $299(46.4)$ \\
\hline Felt in Great Danger of Being Killed ${ }^{*} \$ \uparrow \neq * *$ & $4,674(53.2)$ & $366(77.4)$ & $1,676(78.2)$ & $571(88.7)$ \\
\hline$\geq 2$ of Above ${ }^{* \S+q \neq * *}$ & $2,569(29.2)$ & $301(63.6)$ & $980(45.7)$ & $479(74.4)$ \\
\hline \multicolumn{5}{|c|}{ 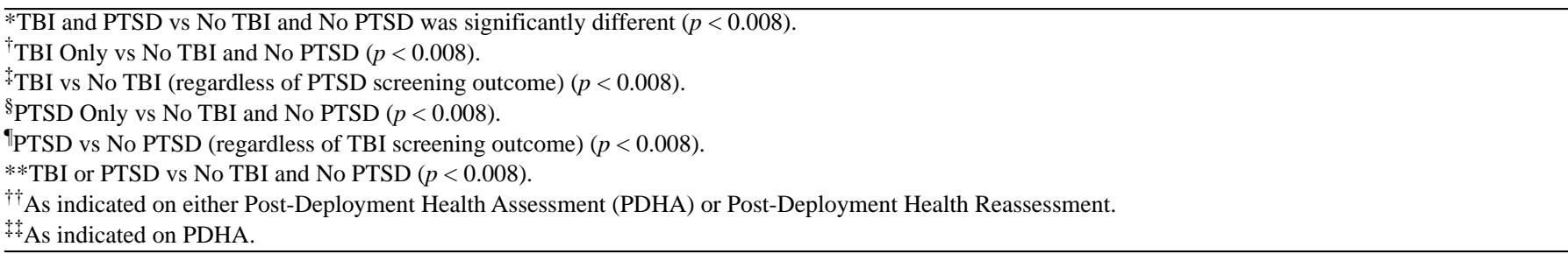 } \\
\hline
\end{tabular}

Table 2.

Postdeployment symptom reporting among Navy/Marine Corps personnel according to posttraumatic stress disorder (PTSD) and/or traumatic brain injury (TBI) screening status $(N=12,046)$. Data shown as mean \pm standard deviation.

\begin{tabular}{lcccc}
\hline $\begin{array}{l}\text { No. of Symptoms } \\
\text { Reported }^{* \dagger}\end{array}$ & $\begin{array}{c}\text { No TBI \& No PTSD } \\
(\boldsymbol{n}=\mathbf{8 , 7 8 5})\end{array}$ & $\begin{array}{c}\text { TBI Only } \\
(\boldsymbol{n}=\mathbf{4 7 3})\end{array}$ & $\begin{array}{c}\text { PTSD Only } \\
(\boldsymbol{n}=\mathbf{2 , 1 4 4 )}\end{array}$ & $\begin{array}{c}\text { TBI \& PTSD } \\
(\boldsymbol{n}=\mathbf{6 4 4})\end{array}$ \\
\hline PDHA & $0.99 \pm 1.93$ & $1.69 \pm 2.55$ & $2.49 \pm 3.13$ & $3.87 \pm 3.92$ \\
PDHRA & $0.76 \pm 1.65$ & $1.83 \pm 2.53$ & $2.73 \pm 3.17$ & $4.43 \pm 4.10$ \\
\hline
\end{tabular}

*Analysis of variance with familywise significance set at $p<0.05$ and individual test significance set at $p<0.008$ (Bonferroni adjustment for multiple comparisons).

${ }^{\dagger}$ All pairwise comparisons are significant.

PDHA = Post-Deployment Health Assessment, PDHRA = Post-Deployment Health Reassessment.

less on the second assessment than the first assessment was the group without either TBI or PTSD.

Across all four samples, symptom percent changes from the PDHA to the PDHRA are presented in Figure 2, stratified by PTSD status. The majority of symptoms appear to decrease during the months following return from deployment for individuals with neither PTSD nor TBI. The greatest percent change observed was the increase in self-reported difficulty making decisions among subjects in the PTSD-only group (91.4\%) and 


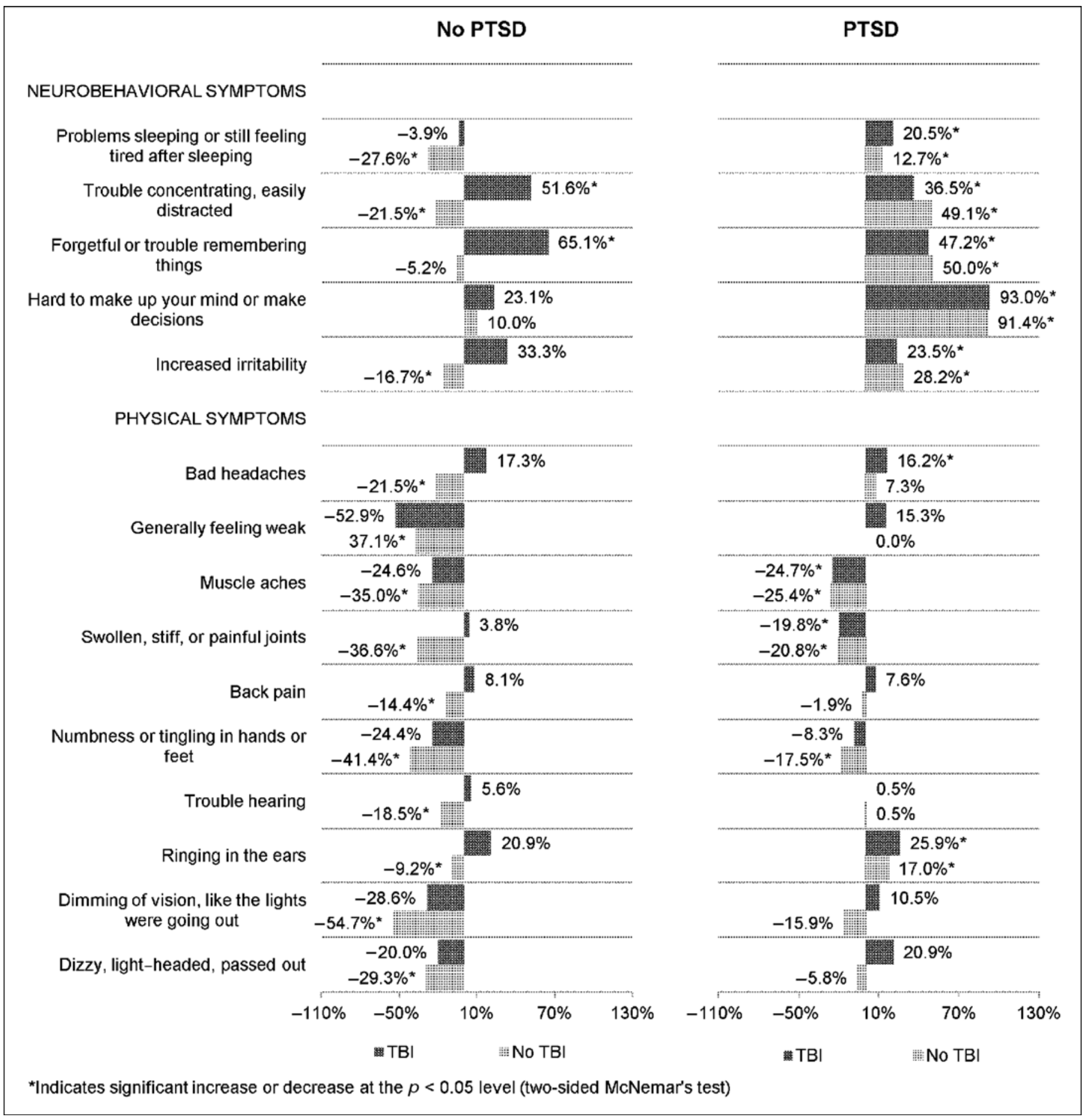

Figure 2.

Percent change from Post-Deployment Health Assessment to Post-Deployment Health Reassessment in reporting of symptoms among Navy/Marine Corps personnel according to posttraumatic stress disorder (PTSD) and traumatic brain injury (TBI) screening status.

subjects in the PTSD and TBI group (93.0\%). Among subjects without PTSD, those with TBI experienced an increase in several neurobehavioral symptoms from the PDHA to the PDHRA, while subjects without TBI experienced a 
decrease. Not surprisingly, both samples with PTSD saw a significant increase in all neurobehavioral symptoms, with a greater than 90 percent increase in reporting of decisionmaking difficulties from the PDHA to the PDHRA. Among the sample of subjects with PTSD, the added presence of TBI appeared to be associated with an even greater increase in reporting symptoms such as problems sleeping, feeling weak, back pain, ringing in the ears, dimming of vision, and dizziness. In sum, patients who did not screen positive for PTSD or TBI reported a decrease in symptoms over time, whereas screening positive for either condition appeared to put individuals at risk for development or worsening of most symptoms with the exception of musculoskeletal symptoms. Additionally, those subjects with both TBI and PTSD appeared to be at an even greater risk for the development or worsening of a number of specific symptoms (Figure 2).

Table 3 shows the adjusted ORs for the presence of each symptom on the PDHRA, given that the symptom was not present on the PDHA. The reference group is the group without TBI or PTSD. With the exception of dimming of vision and feeling weak among TBI-only subjects, all new symptoms reported on the PDHRA had significantly increased (adjusted) odds among samples of subjects with TBI only, PTSD only, and both conditions compared with the sample with neither condition.

Using only the sample with PTSD $(n=2,788)$, the adjusted ORs were computed for each symptom on the PDHRA, given that the symptom was not present on the PDHA. The PTSD and TBI group was referenced against the PTSD-only group. Among subjects with PTSD, those with TBI were significantly more likely to report experiencing all symptoms on the PDHRA with the exception of muscle aches and painful joints. Relatively high ORs (>2.00) were observed for memory problems, headaches, and ringing in the ears. High ORs (>3.00) were observed for dimming of vision and dizziness (results not shown).

\section{DISCUSSION}

The identification of TBI and PTSD is complicated because diagnoses are frequently based on symptom reports that not only cross diagnostic categories but may not occur until several months after the traumatic event. This study found that symptom reporting increased between the two assessments for those screening positive for TBI, PTSD, or both conditions. In contrast, those screening negative for

Table 3.

Adjusted odds ratio (OR) for presence of each symptom on Post-Deployment Health Reassessment, given that symptom was not present on PostDeployment Health Assessment, according to traumatic brain injury (TBI) and posttraumatic stress disorder (PTSD) screening status.

\begin{tabular}{|c|c|c|c|c|}
\hline \multirow{2}{*}{ Symptom } & \multirow{2}{*}{$n$} & \multicolumn{3}{|c|}{ OR* $^{*}$ (95\% Confidence Interval) } \\
\hline & & TBI Only & PTSD Only & TBI \& PTSD \\
\hline \multicolumn{5}{|l|}{$\overline{\text { Neurobehavioral Symptoms }}$} \\
\hline Problems Sleeping or Still Feeling Tired after Sleeping & 9,779 & $3.38(2.53-4.50)^{\dagger}$ & $4.58(3.92-5.35)^{\dagger}$ & $8.28(6.42-10.67)^{\dagger}$ \\
\hline Forgetful or Trouble Remembering Things & 11,077 & $3.69(2.69-5.07)^{\dagger}$ & $4.62(3.88-5.51)^{\dagger}$ & $9.69(7.56-12.42)^{\dagger}$ \\
\hline Hard to Make Up Your Mind or Make Decisions & 11,692 & $2.06(1.14-3.71)^{\dagger}$ & $4.95(3.87-6.32)^{\dagger}$ & $9.63(7.03-13.20)^{\dagger}$ \\
\hline Bad Headaches & 11,142 & $3.30(2.26-4.83)^{\dagger}$ & $3.07(2.48-3.82)^{\dagger}$ & $8.07(6.06-10.75)^{\dagger}$ \\
\hline Generally Feeling Weak & 11,369 & $1.66(0.79-3.49)$ & $2.87(2.10-3.92)^{\dagger}$ & $5.52(3.70-8.23)^{\dagger}$ \\
\hline Muscle Aches & 10,761 & $1.65(1.07-2.53)^{\dagger}$ & $2.38(1.94-2.93)^{\dagger}$ & $3.03(2.21-4.16)^{\dagger}$ \\
\hline Swollen, Stiff, or Painful Joints & 9,855 & $1.97(1.42-2.73)^{\dagger}$ & $2.11(1.76-2.53)^{\dagger}$ & $2.69(2.02-3.57)^{\dagger}$ \\
\hline Back Pain & 9,608 & $1.84(1.37-2.48)^{\dagger}$ & $1.81(1.54-2.14)^{\dagger}$ & $2.75(2.13-3.55)^{\dagger}$ \\
\hline Dimming of Vision, Like Lights were Going Out & 11,819 & $2.63(0.77-9.00)$ & $3.33(1.82-6.08)^{\dagger}$ & $12.32(6.44-23.58)^{\dagger}$ \\
\hline Dizzy, Light-Headed, Passed Out & 11,803 & $4.08(2.13-7.80)^{\dagger}$ & $2.62(1.74-3.93)^{\dagger}$ & $9.36(5.96-14.68)^{\dagger}$ \\
\hline
\end{tabular}


both conditions reported fewer symptoms on the PDHRA than the PDHA. Providers treating undiagnosed servicemembers should be aware that the late appearance or persistence of multiple neurobehavioral and physical symptoms in the months following return from deployment may indicate the presence of TBI or PTSD and should screen for both conditions.

Some investigations have concluded that once PTSD is taken into account, very few symptoms (except for headache) remain associated with mild TBI [5,12]. Our results do not support this finding, especially when looking at emerging or persistent symptoms (i.e., symptoms present approximately 6 mo after deployment). Other researchers have suggested that those with TBI have a greater risk of developing PTSD over time [24]. However, there are findings that do not support this assessment [3]. It may be that both conditions coexist but only TBI is initially diagnosed because the PTSD symptoms have not had time to appear. Also possible is that the TBI or PTSD assessment instruments are not sensitive enough to distinguish one from the other. Given this, developing rehabilitation strategies focused on the symptoms rather than on a firm diagnosis might make more sense. This approach may be more effective because servicemembers may be more willing to receive follow-up treatment for sleeping disorders or difficulty concentrating, for example, than for a diagnosis of PTSD. A symptom-focused treatment, rather than treatment that is diagnosis-based, may be perceived by servicemembers to be less stigmatizing and may improve referral compliance rates [25].

This study used the new TBI assessment module that was added to the PDHA in January 2008, thus providing the ability to identify those who screen positive for blastrelated TBI. Many studies have addressed the underreporting of health issues and experiences by servicemembers immediately following deployment [3-4]. One recent study noted a twofold increase in the rate of self-reported mild TBI between 1 mo before returning from deployment and $1 \mathrm{yr}$ later [12]. To address this delay in reporting, our study identified subjects with potential blast-related TBI by evaluating screening results at two different time points after return from deployment. Because this was not a clinical sample, results may be more representative of the general sample of Navy and Marine Corps men deployed to Iraq, Afghanistan, or Kuwait.

Other strengths of this study include a large $(12,046)$ sample of men exposed to combat and the prospective assessment of symptoms using standardized instruments with validated measures for screening. A number of stud- ies have reported on the presence of symptoms at one point in time following deployment $[5,7,13]$. In this study, we were able to examine subject-specific changes in symptom reporting across multiple time points.

This study has some limitations. We were only able to analyze data from male Navy and Marine Corps personnel $(n=12,046)$, so the results may only be generalized to these groups. Our data included self-reported symptom information; therefore, results are subject to related biases. For example, if a subject experienced a blast-related TBI, memory problems may be present that could affect symptom reporting. Because these assessments are not anonymous, other factors such as personal motivations related to career or disability compensation could have influenced symptom reporting. We also had limited information on type of wound (open- or closedhead TBI, for example) or coinjuries [26], and we could not identify severity of TBI [27]. Additional information on coinjuries would have allowed us to look at the symptom patterns in relation to polytrauma [28-29].

Since roadside bombs and improvised explosive devices are becoming increasingly common in war zones and the injuries experienced as a result are almost uniquely experienced by military personnel, it is important to closely examine the sequelae of blast-related TBI separately from TBI caused by other mechanisms that have been studied in greater detail among civilian samples. Our results suggest that symptoms persist or emerge over time, so initial evaluation and/or treatment of symptoms without follow-up assessment may result in less effective rehabilitation. This represents a problem that will likely grow in scope over time, especially if not recognized or managed initially. Effective resolution requires new assessment tools [6], especially tools that can diagnose both conditions when present [30], and interdisciplinary teams to diagnose, manage, and coordinate treatment for military members returning from combat [31-32]. This study is also consistent with other studies concerning the late appearance of symptoms [3-4]. Military healthcare providers should not rely on either the PDHA or PDHRA alone because symptoms emerge over time [33]. Future studies are needed to describe the chronological development and resolution of symptoms in greater detail. Such studies could potentially benefit from symptom measurements taken at more frequent intervals and over a longer duration. Future studies should also examine the underlying mechanisms through which comorbid PTSD and TBI interact to result in a symptom pattern that is distinctly different from the patterns displayed for either condition alone. 


\section{CONCLUSIONS}

After symptom evaluation of a large sample of deployed U.S. Navy sailors and Marines with combat exposure, this study supports what others have found, specifically that subjects with PTSD, blast-related TBI, or both may experience the development or worsening of symptoms during the months following return from deployment. This study suggests that those who screened positive for both PTSD and TBI reported increased symptoms for most postdeployment health categories except for musculoskeletal symptoms. Our study suggests that providers should consider reevaluating patients, even those who initially appear asymptomatic. Because diagnosis and subsequent referrals for treatment of TBI and PTSD rely on the presence of symptoms, the importance of follow-up evaluation should be recognized. Clinicians may want to communicate to patients who are evaluated as having experienced TBI and/or PTSD that treatments will focus on specific symptoms rather than diagnostic labels.

\section{ACKNOWLEDGMENTS}

\author{
Author Contributions: \\ Study concept and design: C. A. Macera, H. J. Aralis. \\ Acquisition of data: A. J. MacGregor, M. R. Galarneau. \\ Analysis and interpretation of data: H. J. Aralis, C. A. Macera, \\ A. J. MacGregor, M. J. Rauh, M. R. Galarneau. \\ Drafting of manuscript: C. A. Macera, H. J. Aralis. \\ Critical revision of manuscript for important intellectual content: \\ C. A. Macera, H. J. Aralis, M. J. Rauh, A. J. MacGregor, \\ M. R. Galarneau. \\ Statistical analysis: H. J. Aralis.
}

Financial Disclosures: The authors have declared that no competing interests exist.

Funding/Support: This material was based on work supported by the U.S. Navy Bureau of Medicine and Surgery, under Work Unit No. 60818.

Additional Contributions: Dr. Macera is now with the HIV/AIDS Prevention Program Department, Naval Health Research Center, San Diego, California.

Institutional Review: The Naval Health Research Center Institutional Review Board approved this study protocol (NHRC.2009.0020). This research was conducted in compliance with all applicable Federal regulations governing the protection of human subjects.

Participant Follow-Up: The authors do not plan to notify study subjects of the publication of this article because this study is defined as minimal risk to subjects. Existing data were accessed for a large sample of military servicemembers; therefore, contacting each study subject is not practical. Following military guidelines, subjects were told that the results would be published in the future.
Disclaimer: This work represents report 11-442, supported by the U.S. Navy Bureau of Medicine and Surgery, under Work Unit No. 60818. The views expressed in this article are those of the authors and do not reflect the official policy or position of the Department of the Navy, DOD, or the U.S. Government. Approved for public release; distribution is unlimited.

\section{REFERENCES}

1. Tanielian T, Jaycox L, editors. Invisible wounds of war: psychological and cognitive injuries, their consequences, and services to assist recovery. Santa Monica (CA): RAND Corporation; 2008. p. 96-97.

2. Brenner LA, Vanderploeg RD, Terrio H. Assessment and diagnosis of mild traumatic brain injury, posttraumatic stress disorder, and other polytrauma conditions: burden of adversity hypothesis. Rehabil Psychol. 2009;54(3):239-46. [PMID:19702422]

http://dx.doi.org/10.1037/a0016908

3. Bombardier CH, Fann JR, Temkin N, Esselman PC, Pelzer E, Keough M, Dikmen S. Posttraumatic stress disorder symptoms during the first six months after traumatic brain injury. J Neuropsychiatry Clin Neurosci. 2006;18(4):501-8. [PMID:17135375]

http://dx.doi.org/10.1176/appi.neuropsych.18.4.501

4. Milliken CS, Auchterlonie JL, Hoge CW. Longitudinal assessment of mental health problems among active and reserve component soldiers returning from the Iraq war. JAMA. 2007;298(18):2141-48. [PMID:18000197] http://dx.doi.org/10.1001/jama.298.18.2141

5. Hoge CW, McGurk D, Thomas JL, Cox AL, Engel CC, Castro CA. Mild traumatic brain injury in U.S. Soldiers returning from Iraq. N Engl J Med. 2008;358(5):453-63. [PMID:18234750] http://dx.doi.org/10.1056/NEJMoa072972

6. Kennedy JE, Jaffee MS, Leskin GA, Stokes JW, Leal FO, Fitzpatrick PJ. Posttraumatic stress disorder and posttraumatic stress disorder-like symptoms and mild traumatic brain injury. J Rehabil Res Dev. 2007;44(7):895-920. [PMID:18075948] http://dx.doi.org/10.1682/JRRD.2006.12.0166

7. Schneiderman AI, Braver ER, Kang HK. Understanding sequelae of injury mechanisms and mild traumatic brain injury incurred during the conflicts in Iraq and Afghanistan: persistent postconcussive symptoms and posttraumatic stress disorder. Am J Epidemiol. 2008;167(12):1446-52. [PMID:18424429] http://dx.doi.org/10.1093/aje/kwn068

8. Stein MB, McAllister TW. Exploring the convergence of posttraumatic stress disorder and mild traumatic brain injury. Am J Psychiatry. 2009;166(7):768-76. 


\section{[PMID:19448186]}

\section{http://dx.doi.org/10.1176/appi.ajp.2009.08101604}

9. Benge JF, Pastorek NJ, Thornton GM. Postconcussive symptoms in OEF-OIF veterans: factor structure and impact of posttraumatic stress. Rehabil Psychol. 2009;54(3):270-78.

[PMID:19702425]

http://dx.doi.org/10.1037/a0016736

10. Iverson GL, Langlois JA, McCrea MA, Kelly JP. Challenges associated with post-deployment screening for mild traumatic brain injury in military personnel. Clin Neuropsychol. 2009;23(8):1299-1314. [PMID:19882473]

http://dx.doi.org/10.1080/13854040903153902

11. Sayer NA, Rettmann NA, Carlson KF, Bernardy N, Sigford BJ, Hamblen JL, Friedman MJ. Veterans with history of mild traumatic brain injury and posttraumatic stress disorder: challenges from provider perspective. J Rehabil Res Dev. 2009;46(6):703-16. [PMID:20104400]

http://dx.doi.org/10.1682/JRRD.2009.01.0008

12. Polusny MA, Kehle SM, Nelson NW, Erbes CR, Arbisi PA, Thuras P. Longitudinal effects of mild traumatic brain injury and posttraumatic stress disorder comorbidity on postdeployment outcomes in National Guard soldiers deployed to Iraq. Arch Gen Psychiatry. 2011;68(1):79-89. [PMID:21199967] http://dx.doi.org/10.1001/archgenpsychiatry.2010.172

13. Brenner LA, Ivins BJ, Schwab K, Warden D, Nelson LA, Jaffee M, Terrio H. Traumatic brain injury, posttraumatic stress disorder, and postconcussive symptom reporting among troops returning from Iraq. J Head Trauma Rehabil. 2010; 25(5):307-12. [PMID:20042982] http://dx.doi.org/10.1097/HTR.0b013e3181cada03

14. Vanderploeg RD, Belanger HG, Curtiss G. Mild traumatic brain injury and posttraumatic stress disorder and their associations with health symptoms. Arch Phys Med Rehabil. 2009;90(7):1084-93. [PMID:19577020] http://dx.doi.org/10.1016/j.apmr.2009.01.023

15. Deployment Health Clinical Center. Post-Deployment Health Assessment (PDHA) Program (DD Form 2796) [Internet]. Bethesda (MD): Deployment Health Clinical Center; [cited 2011 Oct 14]. Available from:

http://www.pdhealth.mil/dcs/DD_form_2796.asp

16. Deployment Health Clinical Center. Post-Deployment Health Reassessment (PDHRA) Program (DD Form 2900) [Internet]. Bethesda (MD): Deployment Health Clinical Center; [cited 2011 Oct 14]. Available from:

http://www.pdhealth.mil/dcs/pdhra.asp

17. Smith TC, Wingard DL, Ryan MA, Kritz-Silverstein D, Slymen DJ, Sallis JF; Millennium Cohort Study Team. PTSD prevalence, associated exposures, and functional health outcomes in a large, population-based military cohort. Public Health Rep. 2009;124(1):90-102. [PMID:19413031]
18. Iverson KM, Hendricks AM, Kimerling R, Krengel $M$, Meterko M, Stolzmann KL, Baker E, Pogoda TK, Vasterling JJ, Lew HL. Psychiatric diagnoses and neurobehavioral symptom severity among OEF/OIF VA patients with deployment-related traumatic brain injury: a gender comparison. Womens Health Issues. 2011;21(4, Suppl):S210-17.

[PMID:21724143]

http://dx.doi.org/10.1016/j.whi.2011.04.019

19. Prins A, Ouimette P, Kimerling R, Cameron RP, Hugelshofer DS, Shaw-Hegwer J, Thrailkill A, Gusman FD, Sheikh JI. The Primary Care PTSD screen (PC-PTSD): development and operating characteristics. Int J Psychiatry Clin Pract. 2004; 9(1):9-14. http://dx.doi.org/10.1185/135525703125002360

20. King D, Leskin G, King L, Weathers F. Confirmatory factor analysis of the Clinician-Administered PTSD Scale: evidence for the dimensionality of posttraumatic stress disorder. Psychol Assess. 1998;10(2):90-96.

http://dx.doi.org/10.1037/1040-3590.10.2.90

21. Bliese PD, Wright KM, Adler AB, Cabrera O, Castro CA, Hoge CW. Validating the Primary Care Posttraumatic Stress Disorder screen and the Posttraumatic Stress Disorder Checklist with soldiers returning from combat. J Consult Clin Psychol. 2008;76(2):272-81. [PMID:18377123] http://dx.doi.org/10.1037/0022-006X.76.2.272

22. Hoge CW, Auchterlonie JL, Milliken CS. Mental health problems, use of mental health services, and attrition from military service after returning from deployment to Iraq or Afghanistan. JAMA. 2006;295(9):1023-32. [PMID:16507803] http://dx.doi.org/10.1001/jama.295.9.1023

23. Kroenke K, Spitzer RL, Williams JB. The Patient Health Questionnaire-2: validity of a two-item depression screener. Med Care. 2003;41(11):1284-92. [PMID:14583691] http://dx.doi.org/10.1097/01.MLR.0000093487.78664.3C

24. Warden D. Military TBI during the Iraq and Afghanistan wars. J Head Trauma Rehabil. 2006;21(5):398-402. [PMID:16983225] http://dx.doi.org/10.1097/00001199-200609000-00004

25. Hoge CW, Castro CA, Messer SC, McGurk D, Cotting DI, Koffman RL. Combat duty in Iraq and Afghanistan, mental health problems, and barriers to care. N Engl J Med. 2004; 351(1):13-22. [PMID:15229303] http://dx.doi.org/10.1056/NEJMoa040603

26. Helmick KM, Parkinson GW, Chandler LA, Warden DL. Mild traumatic brain injury in wartime. Fed Pract. 2007; 24(10):58-65.

27. Jones E, Fear NT, Wessely S. Shell shock and mild traumatic brain injury: a historical review. Am J Psychiatry. 2007;164(11):1641-45. [PMID:17974926] http://dx.doi.org/10.1176/appi.ajp.2007.07071180

28. Lew HL, Poole JH, Vanderploeg RD, Goodrich GL, Dekelboum S, Guillory SB, Sigford B, Cifu DX. Program development and defining characteristics of returning military in 
JRRD, Volume 49, Number 8, 2012

a VA Polytrauma Network Site. J Rehabil Res Dev. 2007; 44(7):1027-34. [PMID:18075959]

http://dx.doi.org/10.1682/JRRD.2007.05.0073

29. Mernoff ST, Correia S. Military blast injury in Iraq and Afghanistan: the Veterans Health Administration's polytrauma system of care. Med Health R I. 2010;93(1):16-18, 21. [PMID:20481201]

30. Bahraini NH, Brenner LA, Harwood JE, Homaifar BY, Ladley-O’Brien SE, Filley CM, Kelly JP, Adler LE. Utility of the trauma symptom inventory for the assessment of post-traumatic stress symptoms in veterans with a history of psychological trauma and/or brain injury. Mil Med. 2009;174(10): 1005-9. [PMID:19891210]

31. Hill JJ 3rd, Mobo BH Jr, Cullen MR. Separating deploymentrelated traumatic brain injury and posttraumatic stress disorder in veterans: preliminary findings from the Veterans Affairs traumatic brain injury screening program. Am J Phys Med Rehabil. 2009;88(8):605-14. [PMID:19620825] http://dx.doi.org/10.1097/PHM.0b013e3181ae0f83

32. Jaffee MS, Helmick KM, Girard PD, Meyer KS, Dinegar K, George K. Acute clinical care and care coordination for traumatic brain injury within Department of Defense. J Rehabil
Res Dev. 2009;46(6):655-66. [PMID:20104395]

http://dx.doi.org/10.1682/JRRD.2008.09.0114

33. Sharkey JM, Rennix CP. Assessment of changes in mental health conditions among sailors and marines during postdeployment phase. Mil Med. 2011;176(8):915-21. [PMID:21882782]

Submitted for publication July 20, 2011. Accepted in revised form January 27, 2012.

This article and any supplementary material should be cited as follows:

Macera CA, Aralis HJ, MacGregor AJ, Rauh MJ, Galarneau MR. Postdeployment symptom changes and traumatic brain injury and/or posttraumatic stress disorder in men. J Rehabil Res Dev. 2012;49(8):1197-1208.

http://dx.doi.org/10.1682/ JRRD.2011.07.0131

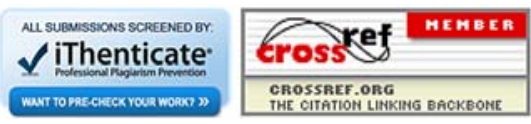

